\title{
Ethical Aspects of Informed Consent in Dementia
}

\author{
Dhruv Parmar \\ Consultant Psychiatrist, Neuropsychiatric Care Centre, Valsad and Government Hospital, \\ Marwad, Daman. \\ Corresponding Author: Dhruv Parmar \\ E-mail: dhruvparmar316@gmail.com
}

\begin{abstract}
Introduction
Informed Consent is an ethical and legal obligation that a medical practitioner or researcher must take in order to explain the treatment plan or enrol a participant in a research trial. In this process the participant or patient is informed about all the aspects of the treatment or trial in detail, which are important for the participant or patient to decide after studying these aspects in detail whether they want to voluntarily confirm their participation in the trial or is willing to undergo the said procedure or treatment. The concept is based on the principle of the Nuremberg Code, The Declaration of Helsinki, and the Belmont Report [1-5].

The informed consent is described in ethical codes and regulations for human subject's research. The goal of the informed consent process is to provide sufficient information to a potential participant, in a language which is easily understood by him/her, so that he/she can make the voluntary decision regarding "to" or "not to" participate in the research study. The same is applicable when an Individual undergoes a medical procedure, surgery or takes certain medications. No individual has the right to infringe a person's fundamental right, thus "Informed Consent" is an important and ethical tool $[1,3]$.
\end{abstract}

\section{Components of an Informed Consent}

An Informed Consent can only be considered to have been given if a person or his/her legal representative have been completely informed about the trial/procedure and having understood the provided information, freely agrees to participate in the study or undergo a procedure.

Thus, the person must possess competence, must be voluntary and not been having to be forced to make a decision, the provision of information must be clear truthful and cover entire details of the said procedure or study, only then will the consent be valid.

\section{Ethical Aspects of Informed Consent in Dementia}

In obtaining an informed consent in patients suffering from Dementia we are faced with a significant challenge, as obtaining a consent depends on the competence and mental capacity of the individual. Certain symptoms of dementia like difficulty in concentration and understanding, problems in short term memory, makes their ability to give informed consent questionable. Furthermore, as age progresses the symptoms may worsen. However, it cannot be assumed that people with dementia are incapable of giving consent. Patients with mild to moderate dementia can interpret, evaluate, and derive meaning from their lives. The law assumes that all Individuals are capable unless there is evidence to the contrary [6-7].

The capacity has to be assessed in reference to the particular decision an individual needs to make at that particular time the decision needs to be made. A person can be deemed to be without capacity if, at the particular time when the decision needs to be made, he or she is unable by reason of mental disability to make a decision on the matter in question or is unable to communicate a decision owing to his or her altered consciousness or any other reason [8]. Also, capacity is not global in scope. Most decisions are made individually by a person, these decisions are often constrained by personal choice, values, socio-cultural influences, education, and occupation, thus, 
they may not be always based on logic or deliberation [9]. Understanding, appreciation, reasoning and expression of a choice are the decision-making abilities that characterise capacity. This ability is not static [10]. Treatment of certain reversible conditions can also improve capacity, fluctuations, medications, delirium, infections, drowsiness, sundowning also effects the ability to make decisions [6-11].

It is established that capacity is required for valid informed consent, although capacity is dependent on cognition, it is not the same as cognition. It is also different from functional activities, for example, a person who is unable to do a certain task may be capable of deciding who can assist them to do the task [6].

Studies have found that impaired decision making was found in $44-69 \%$ residents in nursing homes and nearly all patients with mild to moderate Alzheimer's dementia were impaired at making decisions (component of understanding) but could still perform well as controls on appreciation, reasoning, and choice. Thus, with the preserved ability of making choice and providing reasoning, they can make a decision about daily care but not about complex treatment choices [12-15]. Patients with behavioural variant of frontoparietal dementia may perform well on standard neuropsychological tests but have impaired judgement and decision- making [16]. Patients with amnestic mild cognitive impairment were able to express choice but had impaired appreciation, reasoning and understanding [17].

\section{Assessment of Capacity}

A semi structured direct interview with the patient is used to assess capacity. The patient must have adequate, relevant information regarding the matter to be discussed and an approach of openended questions can be used to evaluate the aspects of decision-making abilities (understanding, choice, appreciation, and reasoning). Reassessment should be done which should be consistent and stable over time [6-18]

The clinician has an ethical responsibility to accurately assess the decision-making capacity of a patient, as it has various ethical, legal, and moral implications. In obtaining a consent the clinician must strike a balance between respecting the autonomy of the patient and acting in their best interest. It can also be possible that this decision be reviewed critically in the court of law. Thus, the process must be rigorous. The capacity is a point along the continuum, which can be rated adequate, inadequate, and marginal. The clinician must also be tactful to communicate the need for further assessment and maintain adequate records [6].

Certain tools can be used for assessing competence to name a few:

1. MacArthur Competence Assessment Tool Treatment: It is frequently used to assess competence and has been validated in patients with dementia which scores for four domains of capacity [19].

2. Assessment of Capacity for Everyday Decision-making: Useful to understand if a person who has a functional deficit understands an appreciates the problem, the risks and benefits of solutions to the problem and can reason through choices about solving it [20].

3. Role of Neuropsychological Tests: The help understand the neural basis of the decisionmaking ability, indicate interventions, and also act as a tool to assess capacity. Bedside tests like executive interview, formal tests like test of conceptualisation, Trials A and fluency test can measure executive functioning. Verbal memory tests are also important to recall information. [6,14, 21-23] The cognitive level of cognitive function and decision ability varies from individual to individual, but it has a significant impact on the patient's judgement regarding their capacity. The Mini Mental Status Examination (MMSE) is a widely used tool of cognition in clinical practice, it is easy to administer and requires no formal training. If used in conjunction with other neuropsychological tests it can improve patient's comprehension of the task to be done [13].

There is currently no single test, which could be considered a gold standard test for capacity assessments. In clinical practice, a combination of clinician's judgment with a structured capacity interview and neuropsychological tests that include executive function tests would be ideal. [6,24] 
Alternatives In case of Incompetence to give Informed consent

A person who fully lacks the capacity to consent to research or a procedure could be for or against participating in research or undergoing the procedure in general. But that does not mean that in informed consent cannot be taken. In such cases 2 alternatives can be considered:

1. Advanced Directives: These are written by competent individuals who wanted to express in writing their wishes about medical treatment they might eventually need in the event of an accident or illness which rendered them incapable of exercising self-determination. In this way, a person's autonomy could be extended into the future well beyond the point that they were able to exercise it. The concept of the advance directive has been further extended to the research situation in some countries but not in most. Advance directives may be legally binding or simply advisory depending on their legal status in each country and sometimes on the nature of the decisions to be made [6].

2. Proxy Decision Making: It is usually in context of healthcare decisions and may be covered with laws or deontological codes. In certain countries proxy decision makers can also consent on behalf of the patient with dementia. In certain situations, the proxy decision maker is made by the means of an advanced directive. In other cases, it could be the patients' relative in the form of spouse, adult child, sibling, or lawful guardian [25].

\section{Conclusion}

A person's capacity to decide and make choices is an important part of who they are and how they wish to live. A person has the right to have an informed consent. Dementia can pose unique challenges in obtaining informed consent. As clinicians it is important to not just assess but ensure that the conditions provided were optimal for level of functioning of the individual to enable them to make a decision. We need to spend time to educate the person and their family, reduce their anxiety, take into consideration the lucid intervals, treatable causes, physical conditions which can interfere with capacity. Overall, the patient's best interests need to be focussed on. All persons irrespective of age enjoy the same liberties, however patients with dementia are more vulnerable and need proper attention. The complexities of their assessment and implications of their judgments need to be taken into consideration to ensure that their interests are protected. Informed consent in dementia requires a fine balance to be ethically and morally correct and preserving the autonomy of the patient.

\section{REFERENCES}

1. International conference on harmonisation of technical requirements for registration of pharmaceuticals for human use. Guideline for good clinical practice E6(R1) June. 1996.

2. Nuremberg Military Tribunal. The Nuremberg Code. JAMA 1996;276(20):1691.

3. Nijhawan LP, Janodia MD, Muddukrishna BS, Bhat KM, Bairy KL, Udupa N, Musmade PB. Informed consent: Issues and challenges. J Adv Pharmaceut Technol Res 2013;4(3):134-40.

4. World Medical Association declaration of Helsinki. Ethical principles for medical research involving human subjects. 2012.

5. The Belmont Report ethical principles and guidelines for the protection of human subjects of research. The National Commission for the protection of human subjects of biomedical and behavioral research; April 18. 1979.

6. Hegde S, Ellajosyula R. Capacity issues and decision-making in dementia. Ann Indian Acad Neurol 2018;19(Suppl 1):S34-9.

7. Wong JG, Clare IC, Gunn MJ, Holland AJ. Capacity to make health care decisions: its importance in clinical practice. Psychol Med 1999;29(2):437-46.

8. British Medical Association. Assessment of Mental Capacity. The Law Society; 2015 Dec 8.

9. Kim SY, Karlawish JH, Caine ED. Current state of research on decision-making competence of cognitively impaired elderly persons. Am J Geriatr Psychiatry 2002;10(2):151-65.

10. Appelbaum PS. Assessment of patients' competence to consent to treatment. New Engl J Med 2007;357(18):1834-40.

11. Grisso T, Appelbaum PS. Assessing competence to consent to treatment: A guide for physicians and other health professionals. Oxford University Press, USA; 1998. 
12. Kim SY, Karlawish JH, Caine ED. Current state of research on decision-making competence of cognitively impaired elderly persons. Am J Geriatr Psychiatry 2002;10(2):151-65.

13. Pruchno RA, Smyer MA, Rose MS, Hartman-Stein PE, Henderson-Laribee DL. Competence of long-term care residents to participate in decisions about their medical care: a brief, objective assessment. The Gerontologist 1995;35(5):622-9.

14. Royall DR, Cordes J, Polk M. Executive control and the comprehension of medical information by elderly retirees. Experiment Aging Res 1997;23(4):301-13.

15. Marson DC, Ingram KK, Cody HA, Harrell LE. Assessing the competency of patients with Alzheimer's disease under different legal standards: A prototype instrument. Arch Neurol 1995;52(10):949-54.

16. Manes F, Torralva T, Ibáñez A, Roca M, Bekinschtein T, Gleichgerrcht E. Decision-making in frontotemporal dementia: clinical, theoretical and legal implications. Dement Geriatr Cogn Disord 2011;32(1):11-7.

17. Okonkwo OC, Griffith HR, Belue K, Lanza S, Zamrini EY, Harrell LE, Brockington JC, Clark D, Raman R, Marson DC. Cognitive models of medical decision-making capacity in patients with mild cognitive impairment. J Int Neuropsychol Soc 2008;14(2):297-308.

18. Karlawish J. Measuring decision-making capacity in cognitively impaired individuals. Neurosignals 2008;16(1):91-8.

19. Grisso T, Appelbaum PS. Comparison of standards for assessing patients' capacities to make treatment decisions. Am J Psychiatry 1995;152(7):1033-7.

20. Lai JM, Gill TM, Cooney LM, Bradley EH, Hawkins KA, Karlawish JH. Everyday decisionmaking ability in older persons with cognitive impairment. Am J Geriatr Psychiatry 2008;16(8):6936.

21. Marson DC, Sawrie SM, Snyder S, McInturff B, Stalvey T, Boothe A, Aldridge T, Chatterjee A, Harrell LE. Assessing financial capacity in patients with Alzheimer disease: A conceptual model and prototype instrument. Arch Neurol 2000;57(6):877-84.

22. Bassett SS. Attention: Neuropsychological predictor of competency in Alzheimer's disease. J Geriatr Psychiatr Neurol 1999;12(4):200-5.

23. Marson DC, Cody HA, Ingram KK, Harrell LE. Neuropsychologic predictors of competency in Alzheimer's disease using a rational reasons legal standard. Arch Neurol 1995;52(10):955-9.

24. Etchells E, Darzins P, Silberfeld M, Singer PA, McKenny J, Naglie G, Katz M, Guyatt GH, Molloy DW, Strang D. Assessment of patient capacity to consent to treatment. J Gen Intern Med 1999;14(1):27-34.

25. Shalowitz DI, Garrett-Mayer E, Wendler D. The accuracy of surrogate decision makers: a systematic review. Arch Intern Med 2006;166(5):493-7.

\section{Acknowledgements: Nil \\ Funding: Nil \\ Conflict of interest: Nil}

